\title{
Characterization of Neural Cell Adhesion Sites: Point Contacts Are the Sites of Interaction between Integrins and the Cytoskeleton in PC12 Cells
}

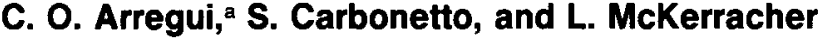 \\ Centre for Research in Neuroscience, Montreal General Hospital Research Institute and McGill University, Montreal, \\ Quebec, H3G 1 A4 Canada
}

\begin{abstract}
As developing or regenerating neurons grow, their axons seek cues in the extracellular matrix that are recognized by integrin receptors. To understand the regulation and structure of neural integrin complexes, we have examined the association of two functionally important integrins, $\alpha 1 \beta 1$ and $\alpha 3 \beta 1$, within PC12 cells. Detergent-resistant cytoskeletal ghosts were prepared from PC12 cells and examined by immunoblotting. In cells maintained in suspension the $\alpha 1$, $\alpha 3$, and $\beta 1$ integrin subunits were solubilized by Triton $X-100$ detergent. In contrast, when cells were grown on collagen or laminin about $50 \%$ of the $\alpha 1$ and $\beta 1$ subunits were retained with the cytoskeleton, but $\alpha 3$ remained soluble. Confocal immunofluorescence microscopy of whole cells demonstrated that all three integrin subunits were expressed in a punctate pattern on the cell surface in point contacts. Point contacts were also found to be the predominant adhesion structure of dorsal root ganglion neurons. After detergent extraction of PC12 cells, the point contacts remained only at the cell-substrate interface. Vinculin, which is found consistently in focal contacts on non-neural cells, showed only a partial colocalization with the point contacts, being expressed mainly at the tips of filopodia and the periphery of cell bodies. Talin showed no obvious codistribution with $\beta 1$ integrin immunoreactivity in point contacts. Immunoreactivity to p125 ${ }^{\text {FAK }}$ was not detected in PC12 cells, although astrocytes, which have both focal contacts and point contacts, have p125 12 ak only at focal contacts. These observations, together with previous data (Turner et al., 1989; Tawil et al., 1993), suggest that point contacts are functional adhesion sites and are structurally distinct from focal contacts found in non-neuronal cells.
\end{abstract}

[Key words: integrin, growth cone, cytoskeleton, focal adhesion kinase, talin, vinculin]

\footnotetext{
Received Mar. 4, 1994; revised Apr. 26, 1994; accepted May 11, 1994.

We thank Paula Wilson for sharing results on primary ncuronal culturcs. This work was supported by grants to L.M. from NSERC and FRSQ and to S.C. from MRC. L.M. and S.C. are members of the Canadian Network of Centers for the Study of Neuronal Regeneration. C.O.A. was a recipient of a Pew Foundation Latin American fellowship.

Correspondence should be addressed to Dr. Lisa McKerracher, Center for Research in Neuroscience, Rm L7 136, Montreal General Hospital, 1650 Cedar Avenue, Montreal, Quebec H3G 1 A4.

aPresent address: Dipartemento de Quimica Biologica, Facultad de Ciencias Quimicas, Universidad Nactional de Cordoba, Ciudad Universitaria cc 61, Cordoba, Argentina.

Copyright (C) 1994 Society for Neuroscience $0270-6474 / 94 / 146967-11 \$ 05.00 / 0$
}

Neuronal cells interact with the extracellular substrate through adhesion molecules, with the integrin receptors forming a major protein class that mediates adhesion to extracellular matrix (ECM) proteins. Functional integrin receptors are formed as $\alpha-$ $\beta$ heterodimers from selected members of the large $\alpha$ and $\beta$ gene families (Hynes, 1992). Many neurons express $\beta$, subunits during development as their dominant ECM receptors. Variations in $\alpha$ subunits dimerized to the same $\beta$ subunit radically alter the specificity of a receptor complex. For example, the $\alpha 5 \beta 1$ integrin is a fibronectin receptor that is highly expressed in developing and regenerating peripheral neurons (Lefcort et al., 1992), while the $\alpha 6 \beta 1$ integrin receptor is a laminin receptor, whose developmental regulation has been well characterized for retinal ganglion cells (Cohen et al., 1989). Other neurons are known to express $\alpha 1 \beta 1$ and $\alpha 3 \beta 1$ intcgrins as laminin/collagen receptors (Toyota et al., 1990; Reichardt and Tomaselli, 1991; Tomaselli et al., 1993). Also, some neurons may express more than one class of laminin receptor, such as PC12 cells, which have $\alpha 1 \beta 1$ and $\alpha 3 \beta 1$ receptors that are both functional (Tomaselli et al., 1990, 1993).

A component essential to elicit appropriate intracellular signaling resides in the relatively short cytoplasmic domain of integrins. The $\beta 1$ cytoplasmic domain interacts with the cytoskeleton as shown by immunocytochemical (Mueller et al., 1989) and biochemical methods (Otey et al., 1990), as well as by analysis of molecular chimeras (Solowska, 1991; Carpen et al. 1992) and deletion of its cytoplasmic domain (Solowska et al., 1989; Hayashi et al., 1990; Reszka et al., 1992; Ylänne et al., 1993). These studies demonstrate that the $\beta 1$ cytoplasmic domain is essential for integrin localization to sites of focal contact. In contrast, dclction of $\alpha$ subunit cytoplasmic domain does not alter integrin aggregation, but cell adhesion and motility are diminished (Bauer et al., 1993; Ylänne et al., 1993). Recent experiments indicate that the $\alpha$ subunit may play an important role in conferring specific cell functions such as motility and ECM contraction (Chan et al., 1992).

In non-neuronal cells integrins form highly ordered substratum adhesions called focal contacts (Burridge et al., 1988). The aggregation of integrins into focal contacts occurs near the termini of stress fibers where specialized assemblies of cytoskeletal proteins are located. The various proteins located specifically at focal contacts include talin and vinculin, as well as a focal contact protein tyrosine kinase, p125 FAK (Burridge et al., 1988; Otey et al., 1990; Luna and Hitt, 1992; Schaller et al., 1992). In addition to focal contacts, integrins are also found in smaller punctate deposits called point contacts. These are especially 
Suspension

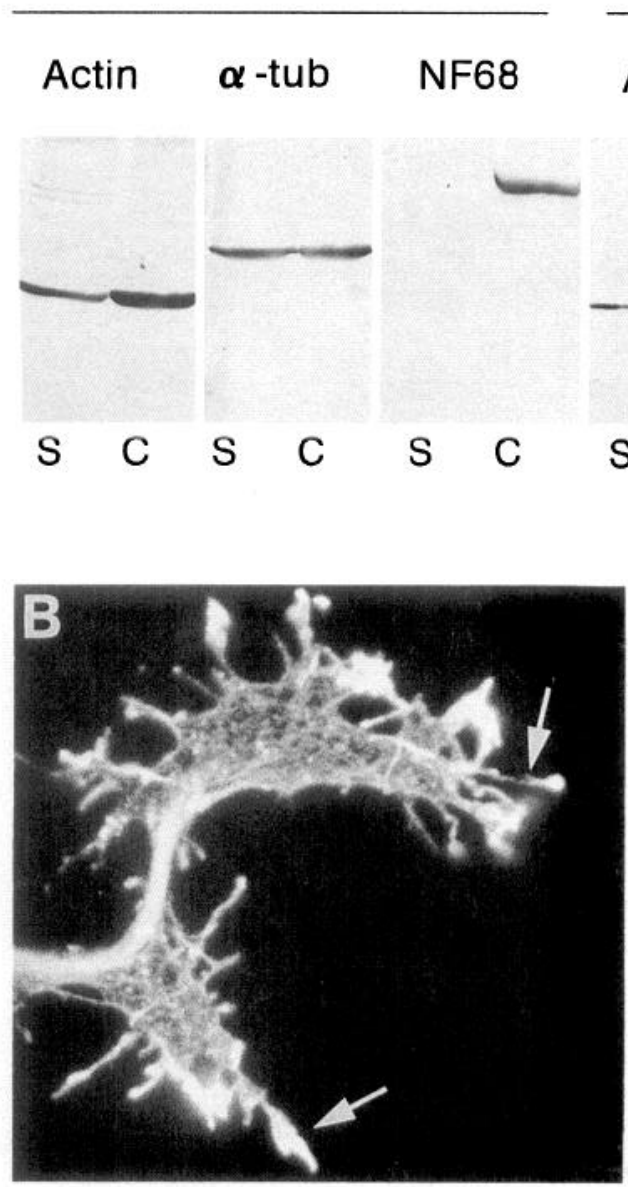

Attached

Actin $\quad \alpha$-tub $\quad$ NF68
Figure 1. The detergent-resistant cytoskeleton examined in cells grown in suspension or on laminin. $A$, Immunoblot showing the actin, $\alpha$-tubulin, and neurofilament (NF68) content of soluble $(S)$ and cytoskeleton $(C)$ fractions after extraction in CSB. Over $50 \%$ of the tubulin and actin, and essentially all of neurofilament protein, are retained with the cytoskeleton from cells grown under the two conditions. Total amounts of soluble and cytoskeletal proteins were electrophoresed on $10 \%$ polyacrylamide gels and probed on Western blots with monoclonal antibodies, and then visualized with an alkaline phosphatase colorimetric reaction. On the right is indicated $\mathrm{M}_{\mathrm{r}} \times 10^{3}$. $B$ and $C$, Immunocytochemistry of cytoskeletal ghosts from $\mathrm{PC} 12$ cell growth cones on laminin-coated coverslips. Actin was visualized with rhodamineconjugated phalloidin $(B)$ or tyrosinated tubulin with the monoclonal antibody YL $1 / 2(C)$. Arrows indicate filopodia where tyrosinated microtubules extend to their tips. Scale bar, 20 $\mu \mathrm{m}$.

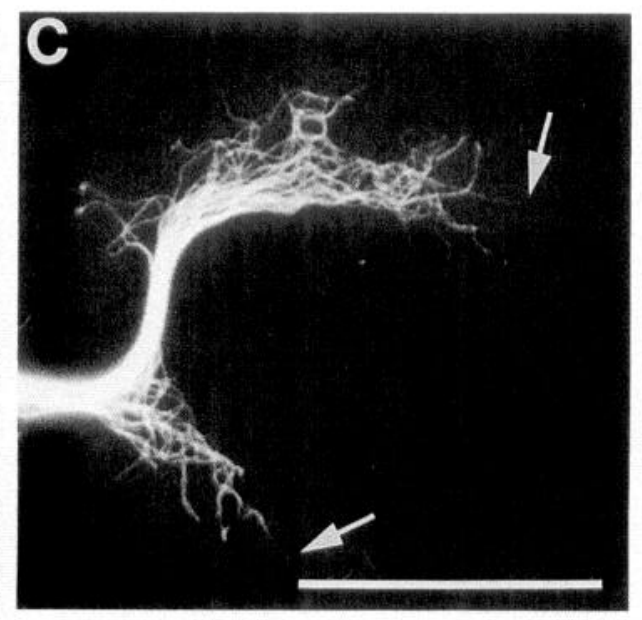

numerous in transformed fibroblasts (Bershadsky et al., 1985; Nermut et al., 1991) and normal rat astrocytes (Tawil et al., 1993). It is not known whether the protein assemblies underlying these different contacts are similar.

To understand how integrins in neuronal cells may function, we have chosen to study the sites of integrin-cytoskeleton interactions in PC12 cells. Studies of PC12 cells have provided details about neurite substrate interactions through $\alpha 1 \beta 1$ and $\alpha 3 \beta 1$ integrins (Tomaselli et al., 1988, 1990; Letourneau et al., 1992), and have served as a model to study the assembly of the cytoskeleton and signal transduction pathways during neurite outgrowth. We have compared the distribution and morphology of integrin receptors in detergent-extracted cells grown in the presence or absence of ligand to determine how cell-substrate interactions influence the association of $\alpha 1 \beta 1$ and $\alpha 3 \beta 1$ integrins with the cytoskeleton. We report here that $\beta 1, \alpha 1$, and $\alpha 3$ integrins are present in point contacts in PC12 cells, but that only the $\alpha 1 \beta 1$ receptor forms a tight association with the cytoskeleton on the lower surface of cells grown on laminin or collagen. Furthermore, the protein composition of point contacts is distinct from that of focal contacts present in other cell types.

\section{Materials and Methods}

Cell culture. PC12 cells obtained from ATCC were cultured in RPMI 1640 containing $10 \%$ heat-inactivated horse serum, $5 \%$ fetal bovine serum, $25 \mathrm{U} / \mathrm{ml}$ penicillin, and $25 \mu \mathrm{g} / \mathrm{ml}$ streptomycin (GIBCO-Bethesda Research Labs, Burlington, Ontario) (Greene et al., 1987). Cell stocks primed with NGF were used for all experiments unless stated, and were obtaincd by growing cells for 1 week in medium with $50 \mathrm{ng} /$ $\mathrm{ml}$ 2.5S NGF (UBI, Lake Placid, NY). Cells maintained in suspension were incubated with gentle shaking in flasks coated with $10 \mathrm{mg} / \mathrm{ml} \mathrm{BSA}$. Cells grown on adhesive substrates were plated onto $100 \mathrm{~mm}$ dishes coated with one of the following substrates: (1) $15 \mu \mathrm{g} / \mathrm{ml}$ rat tail collagen in $70 \%$ ethanol, dried onto plates overnight (Greene et al., 1987); (2) $20 \mu \mathrm{g} / \mathrm{ml}$ laminin purified from Engelbreth-Holm-Swarm sarcoma incubated in PBS $(0.010 \mathrm{~m}$ phosphate buffer, $\mathrm{pH} 7.4,0.140 \mathrm{M} \mathrm{NaCl})$ for $2 \mathrm{hr}$; (3) $500 \mu \mathrm{g} / \mathrm{ml}$ poly-L-lysine (Sigma Chemical Co., St. Louis, MO) incubated in $0.2 \mathrm{M}$ boric acid, $0.05 \mathrm{M}$ sodium borate, $\mathrm{pH} 8.3$ for $2 \mathrm{hr}$. The plates were washed before adding growth medium. Primary neuronal cultures were plated on laminin as described (Carbonetto et al., 1987).

Cytochalasin D at 0.010 M (Calbiochem, San Diego, CA) and colchicine at $0.050 \mathrm{M}$ (Sigma) were prepared in $100 \%$ dimethyl sulfoxide and used at 1:1000 dilution in the culture medium.

Antibodies. Monoclonal antibody $3 \mathrm{~A} 3$ (IgG affinity purified), called here anti- $\alpha 1$ antibody, was raised against PC12 cells (Turner et al., 1989) and recognizes the $\alpha 1$ integrin subunit (Tawil et al., 1990, Tomaselli et al., 1990). Polyclonal anti- $\beta 1$ antiserum was made to a purified rat $\beta 1$ integrin subunit (Tawil et al., 1990). Polyclonal anti- $\alpha 3$ antibody (IgG affinity purified) was prepared against a peptide derived from the cytoplasmic domain sequence of the chicken $\alpha 3$ integrin (de Curtis et al., 1991), and was a gift from Dr. Louis F. Reichardt, University of California, San Francisco. Monoclonal antibodies against $\alpha$-tubulin (clone DM1A), vinculin (clone hVIN-1), talin (clone 8d4), and NF68 (clone NR4) were obtained from Sigma Chemical Co. (St. Louis, MO), and 


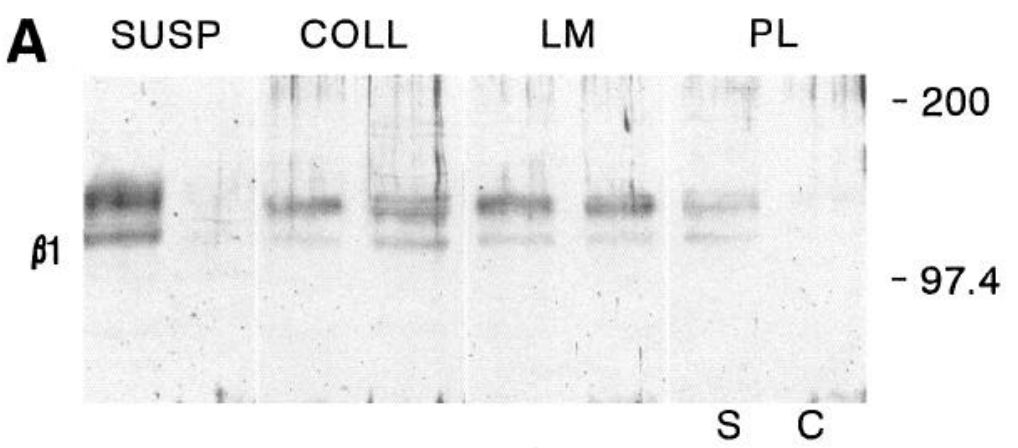

B
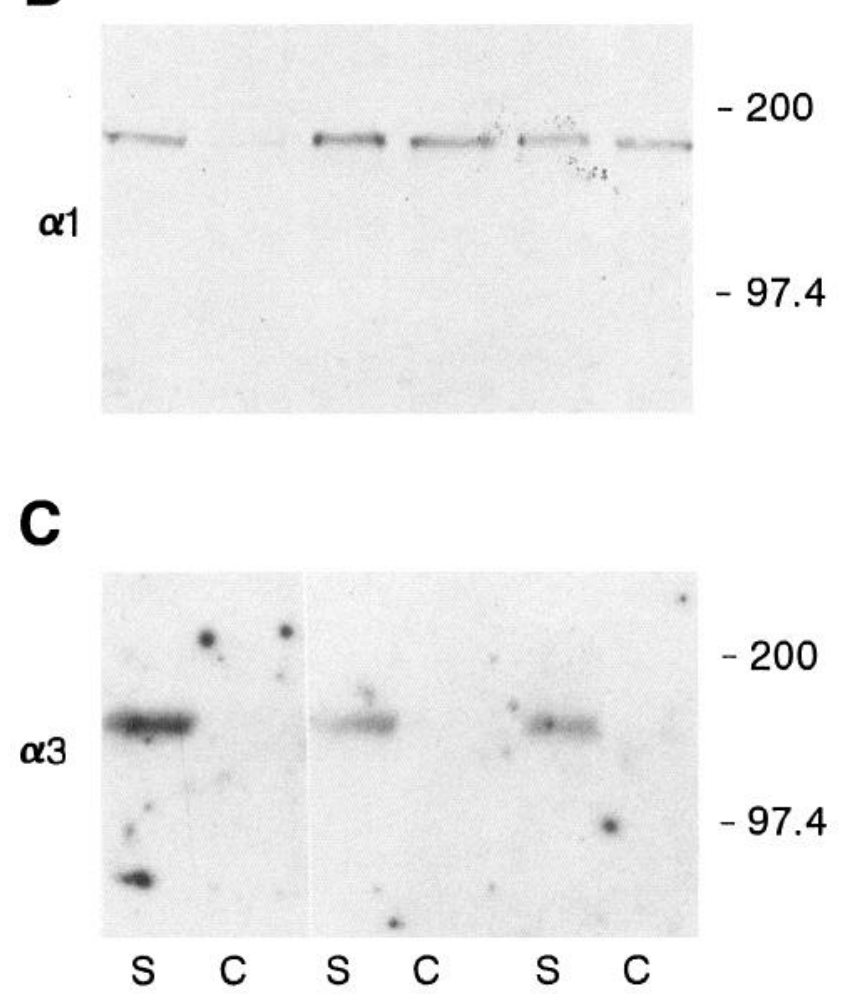
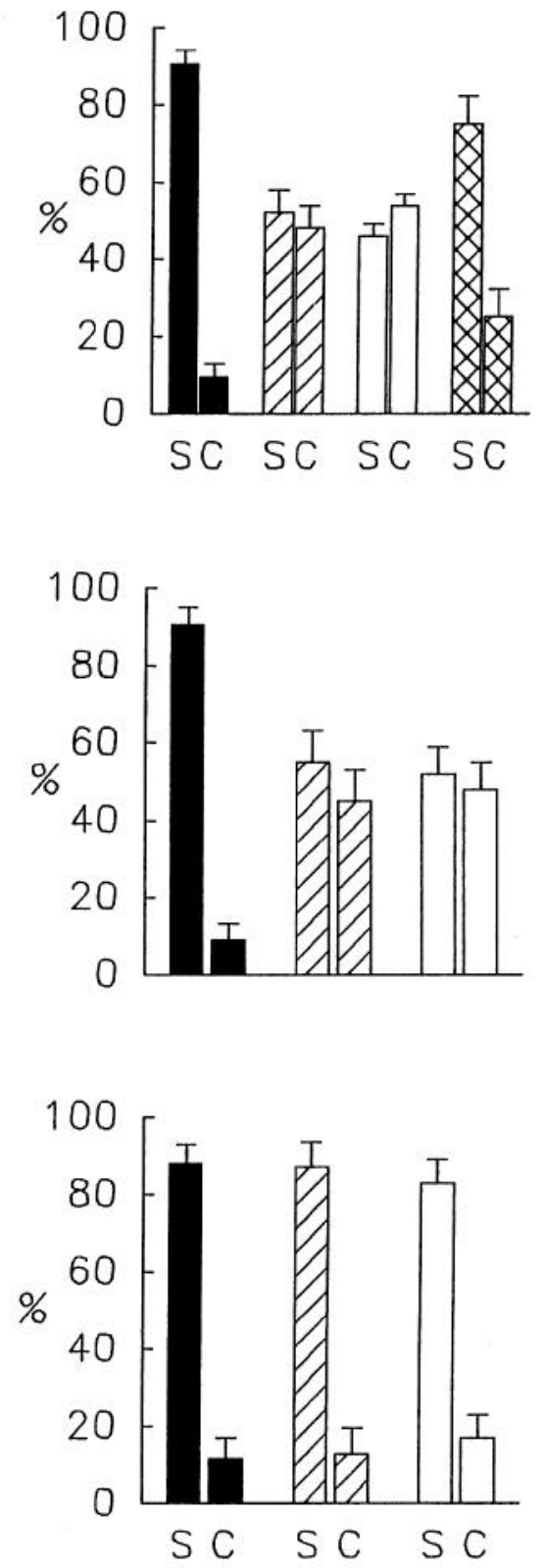

Figure 2. Analysis of the distribution of $\beta 1, \alpha 1$, and $\alpha 3$ integrin subunits in soluble and cytoskeleton fractions. PC12 cells cultured in suspension $(S U S P)$, or on collagen $(C O L L)$, laminin $(L M)$, or polylysine $(P L)$ were extracted with CSB and the soluble $(S)$ and cytoskeleton $(C)$ fractions obtained were electrophoresed on $7 \%$ polyacrylamide gels. Proteins transferred to nitrocellulose were probed with anti- $\beta 1(A)$, anti- $\alpha 1(B)$, or anti$\alpha 3(C)$ antibodies followed by alkaline phosphatase-conjugated second antibodies and NBT/BCIP $(A$ and $B)$ or ${ }^{125}$ I-labeled second antibody $(C)$. Only on laminin and collagen substrates are $\beta 1$ and $\alpha 1$ subunits from attached PC12 cells retained with the cytoskeleton. The $\alpha 3$ subunit was solubilized under all growth conditions. To the right is indicated $\mathrm{M}_{\mathrm{r}} \times 10^{3}$. Histograms on the right show the relative amounts of subunits within any one set of cultures (SUSP, COLL, LM or $P L$ ) by summarizing densitometric data \pm SD from at least three different blots that were visualized with iodinated second antibodies. $Y$-axis is the percentage of total integrin protein found in the soluble $(S)$ or cytoskeletal $(C)$ fractions.

anti-focal adhesion kinase (p125 FAK) antibody (clone 2A7) was purchased from UBI (Lake Placid, NY). Actin was detected with rhodamine-phalloidin (Sigma) or with a monoclonal antibody (clone C4) from Boehringer Mannheim Canada Ltd. Tyrosinated tubulin was detected with the YL 1/2 monoclonal antibody (Serotec, UK).

Cell extraction. The cytoskeleton stabilizing buffer (CSB) used to extract cells contained $0.010 \mathrm{~m}$ PIPES, pH $6.8,0.050 \mathrm{M} \mathrm{KCl}, 0.010 \mathrm{M}$ EGTA, $0.003 \mathrm{M} \mathrm{MgCl}_{2}, 2 \mathrm{M}$ glycerol, $0.001 \mathrm{M}$ PMSF, $50 \mu \mathrm{g} / \mathrm{ml}$ leupeptin, $50 \mu \mathrm{g} / \mathrm{ml}$ aprotinin, and $1 \% \mathrm{TX}-100$. The buffer was warmed to $37^{\circ} \mathrm{C}$ before addition to cells, and the detergent:protein ratio $(w / w)$ ranged between 10:1 and 12:1.

Cells grown in suspension for $1-2 \mathrm{~d}\left(10^{7}\right.$ cells) were collected by centrifugation and washed once with Hanks' balanced salt solution (HBSS) at $37^{\circ} \mathrm{C}$. The pellet was gently resuspended and extracted for $2 \mathrm{~min}$ in
$2 \mathrm{ml} \mathrm{CSB}$ at $37^{\circ} \mathrm{C}$. The insoluble cytoskeleton and soluble proteins were separated by centrifugation at room temperature for $3 \mathrm{~min}$ at $5000 \times$ $g$. The pellet was resuspended using a syringe with a 25 gauge needle in $2 \mathrm{ml}$ of solubilization buffer (SB) composed of $0.010 \mathrm{M}$ Tris- $\mathrm{HCl}, \mathrm{pH}$ $7.4,0.010 \mathrm{M} \mathrm{NaCl}, 0.003 \mathrm{M} \mathrm{MgCl}_{2}, 1 \%$ TX-100, 0.5\% SDS, 1 mм PMSF, $50 \mu \mathrm{g} / \mathrm{ml}$ leupeptin and $50 \mu \mathrm{g} / \mathrm{ml}$ aprotinin, and clarified by centrifugation at $15,000 \times g$ at $4^{\circ} \mathrm{C}$ for $5 \mathrm{~min}$.

Cells grown on collagen, laminin, or polylysine for $2 \mathrm{~d}$ (about $3 \times$ $10^{6}$ cells/dish) were rinsed once with HBSS, once with CSB without $\mathrm{TX}-100$, and extracted for $2 \mathrm{~min}$ with $2 \mathrm{ml}$ of CSB at $37^{\circ} \mathrm{C}$. The solubilized material was gently removed and centrifuged at room temperature for $3 \mathrm{~min}$ at $5000 \times \mathrm{g}$. The adherent cytoskeletons were gently rinsed with $2 \mathrm{ml}$ of CSB $37^{\circ} \mathrm{C}$ without TX-100 and then scraped into $2 \mathrm{ml}$ of CSB buffer. This sample was passed through a 25 gauge needle 
several times and centrifuged to clarify the solubilized cytoskeleton. Soluble and cytoskeleton fractions were diluted with $1 / 3$ vol of $3 \times$ gel sample buffer with or without 2-mercaptoethanol.

Immunoblotting. Equivalent volumes of the soluble and cytoskeleton fractions ( $30-50 \mu \mathrm{g}$ protein/lane) were separated by SDS-PAGE, transferred to nitrocellulose for $70 \mathrm{~min}$ at $100 \mathrm{~V}$ in $0.020 \mathrm{M}$ Tris, $0.150 \mathrm{M}$ glycine, $\mathrm{pH} 8.3,20 \%$ methanol, and $0.1 \%$ SDS, and fixed to the nitrocellulose filters with $25 \%$ isopropyl alcohol, $10 \%$ acetic acid for $15 \mathrm{~min}$. Filters were blocked with $3 \%$ BSA in TBS $(0.050 \mathrm{~m}$ Tris- $\mathrm{HCl}, \mathrm{pH} 7.4$, $0.150 \mathrm{M} \mathrm{NaCl}$ ). Primary antibodies were incubated overnight in TBS, $1 \%$ BSA, and $0.1 \%$ Nonidet P40. Immunocomplexes were detected either using alkaline phosphatase-conjugated second antibodies and NBT/BCIP substrates (Schoenfeld et al., 1989), peroxidase-conjugated second antibodies followed by 1:1 mix of reagents for enhanced chemiluminescence (Amersham Canada Ltd., Oakville, Ontario), or incubation with $0.5 \mu \mathrm{Ci} / \mathrm{ml}^{125} \mathrm{I}$-conjugated protein $\mathrm{A}$ or anti-mouse antibody (ICN Biomedicals Canada Ltd.). Autoradiograms were analyzed by densitometry (U.S. Biochemicals SciScan 5000, Cleveland, OH).

Immunofluorescence and confocal microscopy. About $5 \times 10^{3} \mathrm{NGF}$ primed PC12 cells were plated on coverslips coated with laminin. Cells were cultured for $48 \mathrm{hr}$ before being processed as either whole cells or cytoskeletons. For whole-cell preparations the cells were rinsed twice with PBS and then fixed at room temperature for $15 \mathrm{~min}$ with $3.7 \%$ paraformaldehyde in $0.10 \mathrm{~m}$ phosphate buffer, $\mathrm{pH}$ 7.4. For cytoskeleton preparations, the cells were rinsed with CSB without TX-100, extracted for 2 min with CSB containing $0.5 \%$ TX-100, rinsed gently with CSB without TX-100, and fixed as above. Cells grown in suspension were fixed and then plated onto poly-L-lysine-coated coverslips. All fixed specimens were incubated with $0.10 \mathrm{M}$ glycine in $0.050 \mathrm{M}$ Tris- $\mathrm{HCl}(\mathrm{pH}$ $7.4) 20 \mathrm{~min}$, and then $3 \%$ BSA in PBS $30 \mathrm{~min}$. Primary antibodies and FITC- or rhodamine-conjugated second antibodies (Jackson Immunoresearch Labs, Inc., West Grove, PA) were incubated at $37^{\circ} \mathrm{C}$ in steps of $60 \mathrm{~min}$ each. Modifications to this sequence were the following: (1) the anti- $\beta 1$ antibody was diluted in culture medium, incubated with alive cells for $45 \mathrm{~min}$ at $37^{\circ} \mathrm{C}$, and washed three times with PBS before processing as for whole cells or cytoskeletons; (2) the anti- $\alpha 3$ antibody incubation was carried out in whole cells permeabilized with $0.5 \% \mathrm{TX}$ 100 in PBS for 2 min after fixation. All specimens were mounted in $85 \%$ glycerol containing $1 \mathrm{mg} / \mathrm{ml}$ paraphenylenediamine in $0.20 \mathrm{M}$ Tris$\mathrm{HCl}$ buffer, $\mathrm{pH} 8.5$.

Slides were analyzed with a conventional epifluorescence microscope (Nikon Canada Instruments Inc.) or with a confocal laser scanning microscope (Leica Canada Inc.) using a Neofluor $100 \times, 1.32 \mathrm{NA}$ objective. Confocal images were photographed from the monitor screen using Kodak TMAX 100 ASA film, and epifluorescence micrographs were taken with Kodak TMAX P3200 film.

\section{Results}

\section{Distribution of integrin subunits in detergent-resistant} cytoskeletons and soluble extracts

Integrin receptor interactions with the cytoskeleton were analyzed in $\mathrm{PC} 12$ cell cultures extracted with a cytoskeleton-stabilizing buffer (CSB) containing 1\% Triton-X 100. This buffer leaves behind a cellular ghost containing nuclei and polymerized cytoskeletal proteins while extracting most membrane and cytosolic proteins. To confirm whether the extraction procedure efficiently retained cytoskeletal proteins under different culture conditions, the presence of $\alpha$-tubulin, actin, and neurofilament protein was assessed. Essentially, all of the neurofilament and about half of the total actin and $\alpha$-tubulin were retained in the cytoskeletal ghosts prepared from cells grown in suspension (Fig. $1 A$ ). Moreover, following treatment of cells attached to collagen (Fig. $1 B$ ) or laminin (not shown) with CSB, the actin and neurofilament were similar to that of cells in suspension while tubulin was more enriched in cytoskeletons. These results are consistent with previous data (Morris and Lasek, 1984; Drubin et al., 1988) and show that the expected amounts of these proteins are retained with the cytoskeleton under our extraction conditions. Further, tyrosinated microtubules, the dynamic microtubule population (Arregui et al., 1991) (Fig. 1C) and pol-

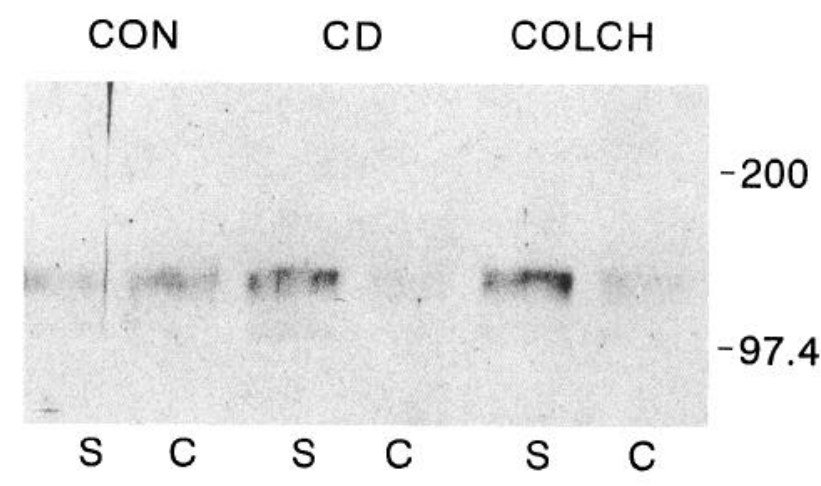

Figure 3. Disruption of interactions between integrin receptors and the cytoskeleton by colchicine or cytochalasin D. PC1 2 cells grown on collagen were incubated with either $10 \mu \mathrm{M}$ cytochalasin $\mathrm{D}(C D)$ or 50 $\mu \mathrm{M}$ colchicine $(C O L C H)$ in $0.1 \%$ DMSO, or $0.1 \%$ DMSO $(C O N)$ as control, for $2 \mathrm{hr}$ before extraction. Soluble $(S)$ and cytoskeleton $(C)$ fractions were separated by electrophoresis, transferred to nitrocellulose, and probed with anti- $\beta 1$ antibody. Immunoreaction was visualized by enhanced chemiluminescence. To the right is indicated $\mathrm{M}_{\mathrm{r}} \times 10^{3}$.

ymerized actin (Fig. $1 B$ ) were well preserved and visible in some growth cone filopodia.

Antibodies specific for the three known integrin receptor subunits in PC12 cells (Tomaselli et al., 1988) were used to probe Western blots. The specificity of the monoclonal anti- $\alpha 1$, and the polyclonal anti- $\alpha 3$ and anti- $\beta 1$ antibodies used in this study have been characterized previously (Turner et al., 1989; Tawil et al., 1990; Tomaselli et al., 1990; de Curtis et al., 1991). The anti- $\beta 1$ antibody recognized the $\beta 1$ subunit as a major band at $135 \mathrm{kDa}$, and other minor bands at about $116 \mathrm{kDa}$, after separation under reducing conditions (Fig. 2A). These additional $\beta 1$ bands might represent under glycosylated forms of the $\beta 1$ subunit (Akiyama and Yamada, 1987) that were not detected previously by immunoprecipitation of surface-labeled proteins from rat astrocytes (Tawil et al., 1993). The $\alpha 1$ subunit was detected as a single band of $180 \mathrm{kDa}$ under reducing conditions (Fig. 2B). The $\alpha 3$ subunit, examined under nonreducing conditions, was identified as a single band of $150 \mathrm{kDa}$ (Fig. $2 C$ ). Extraction of cells grown in suspension or on polylysine showed about $90 \%$ of the $\alpha 1, \alpha 3$, and $\beta 1$ integrin subunits were present in the detergent-soluble fraction (Fig. 2). When cells were grown on either collagen or laminin, the $\alpha 3$ subunit distributed similarly into the soluble fraction (Fig. $2 C$ ), whereas about half of the $\alpha 1$ and $\beta 1$ subunits were retained with the detergent-resistant cytoskeleton (Fig. 2A,B). All of these experiments were done with PC12 cells treated with NGF. Similar results were obtained with cells that were not treated with NGF. Thus, the integrins of cells in suspension are not strongly associated with the cytoskeleton, and NGF treatment and adhesion of cells to polylysine is not sufficient to change the integrin distribution. Following cell attachment to collagen or laminin, a portion of $\alpha 1$ $\beta 1$ subunits appears to associate with the cytoskeleton, while the $\alpha 3$ subunit remains in the soluble fraction.

In further experiments, cells were incubated with cytoskeletal poisons prior to extraction to determine whether association of the $\alpha 1$ and $\beta 1$ integrin subunits with the cytoskeletal fraction was dependent on an intact microtubule or microfilament network. Both cytochalasin D and colchicine, compounds that disrupt microfilaments and microtubules, respectively, rendered most of the $\beta 1$ (Fig. 3) and $\alpha 1$ subunits detergent soluble. The effective disruption of microtubules and microfilaments by the 

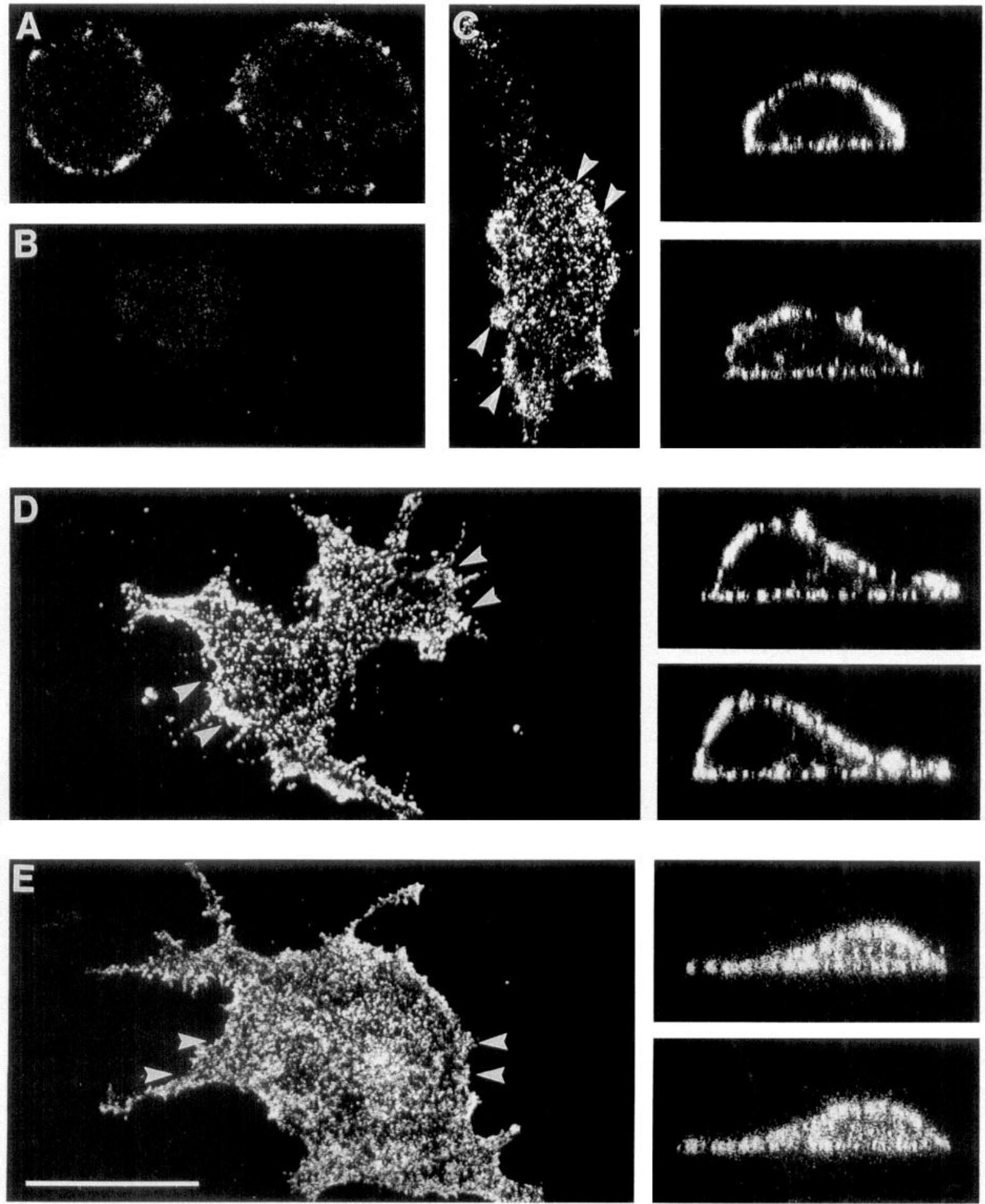

Figure 4. Confocal images showing the integrin localization in whole cells cultured in suspension $(A$ and $B)$ or attached to laminin $(C-E)$. Cells were immunoreacted with anti- $\beta 1(A$ and $C)$, anti- $\alpha 1(D)$ or anti- $\alpha 3(E)$ antibodies. $A$, The surface distribution of $\beta 1$ immunoreactivity in three equatorial $0.7 \mu \mathrm{m}$ optical sections, taken parallel to the coverslip, and summed. $B$, Second antibody control. $C-E$, Left panels show optical sections taken parallel to the substratum at the level of the lower cell surface. Note the uniform punctate distribution of the three integrin subunits. Right panels show optical sections of the same cells taken perpendicular to the substratum (arrowheads indicate the positions). Note that point contacts are uniformly present on the upper and lower cell surfaces. Scale bar, $20 \mu \mathrm{m}$.

drugs was confirmed by their effect on solubilizing much of the tubulin and actin, respectively. Therefore, the $\alpha 1$ and $\beta 1$ subunit shift to the cytoskeletal fraction following adhesion requires an intact microtubule and microfilament framework.
Integrin distribution on whole cells and insoluble cytoskeleton

Integrin localization on the cell surface was studied to compare the distribution of the detergent-resistant and detergent-soluble 

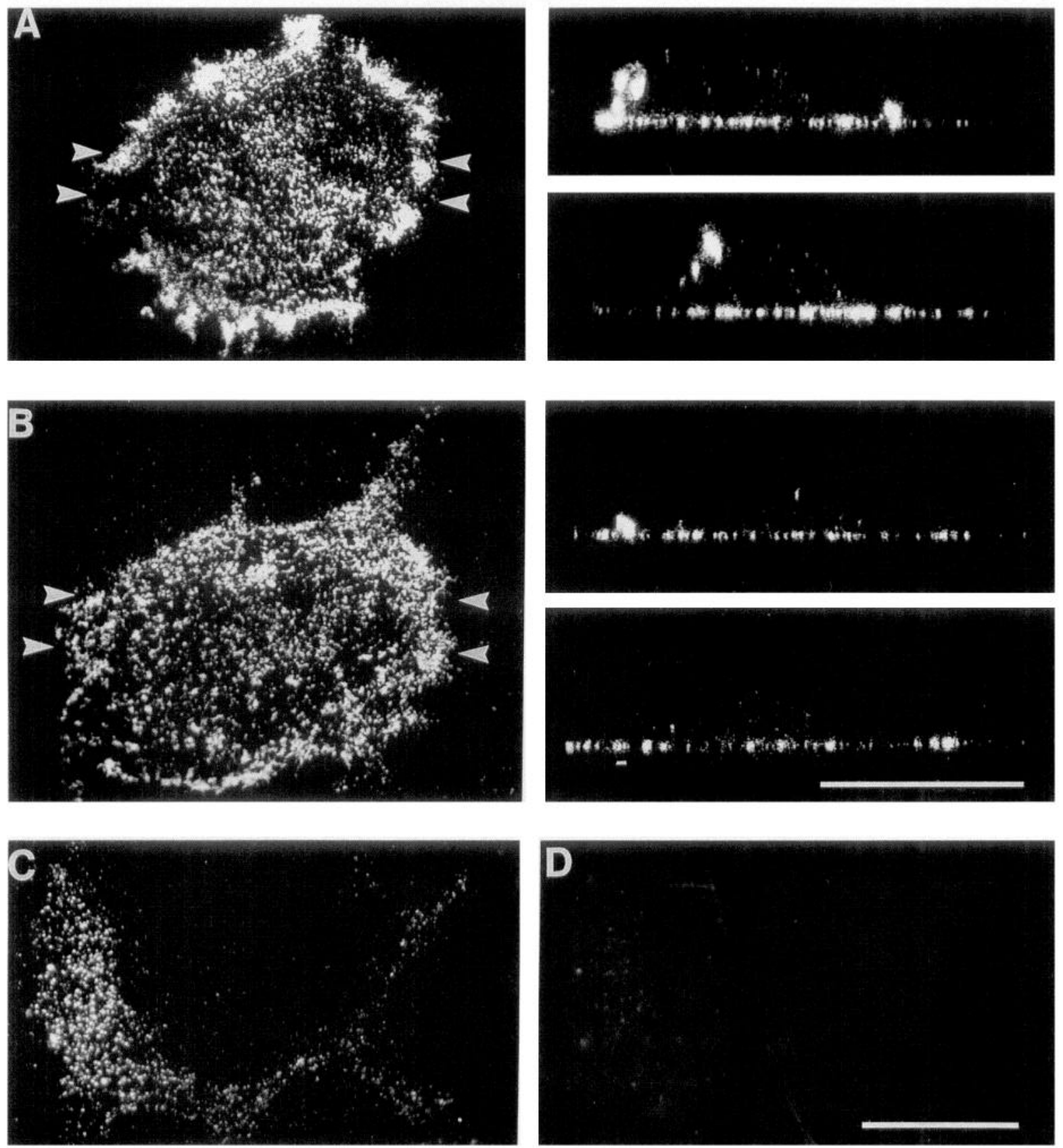

Figure 5. Distribution of $\beta 1, \alpha 1$, and $\alpha 3$ integrin subunits in cytoskeletal ghosts of cells grown on laminin. Confocal analysis was performed after labeling with anti- $\beta 1(A)$ or anti- $\alpha 1(B)$ antibodies. $A$ and $B$, The left panels show optical sections taken parallel to the substratum and at the level of the lower cell surface. The cytoskeleton retains abundant point contacts composed of $\beta 1$ and $\alpha 1$ integrin subunits. Right panels show sections of the same cells taken perpendicular to the substratum (arrowheads indicate positions). Note the high density of point contacts at the lower cell surface and near absence on the upper surface. $C$ and $D$, Double labeling with anti- $\alpha 1(C)$ and anti- $\alpha 3(D)$ antibodies shows that the $\alpha 1$ subunit is retained with the cytoskeleton but $\alpha 3$ immunoreactivity is lost. Scale bars, $20 \mu \mathrm{m}$.

integrins. First, we examined the $\beta 1$ integrin immunoreactivity on the somata of unextracted cells maintained in suspension or grown on laminin. Confocal sections of cells cultured in suspension exhibited $\beta 1$ immunoreactivity on the cell surface (Fig. $4 A$ ). When cells were plated on collagen or laminin, a more uniformly distributed punctate immunoreactivity was observed (Fig. $4 C$ ). The same pattern of cell surface immunoreactivity was observed with the three antibodies to the different integrin subunits (Fig. $4 C, D, E$ ). All integrin immunoreactivity was punctate and resembled the point contacts described in other cells (Nermut et al., 1991, Tawil et al., 1993). Elongated integrin immunoreactivity typical of focal contacts, was absent. Confocal sections taken vertical to the substratum ( $x, z$-planes), showed that the punctate distribution of $\alpha 1, \alpha 3$, and $\beta ; 1$ subunits was uniform in both lower and upper surfaces of the cell (Fig. 4C,D,E, right panels) with some intracellular immunoreactivity to $\alpha 3$ (Fig. $4 E$, right panel).

The distributions of cytoskeleton-associated $\beta 1$ and $\alpha 1$ integrin subunits were examined on Triton- $\mathrm{X}$-extracted cells that were grown on laminin. In parallel sections (x,y-plane) at the 


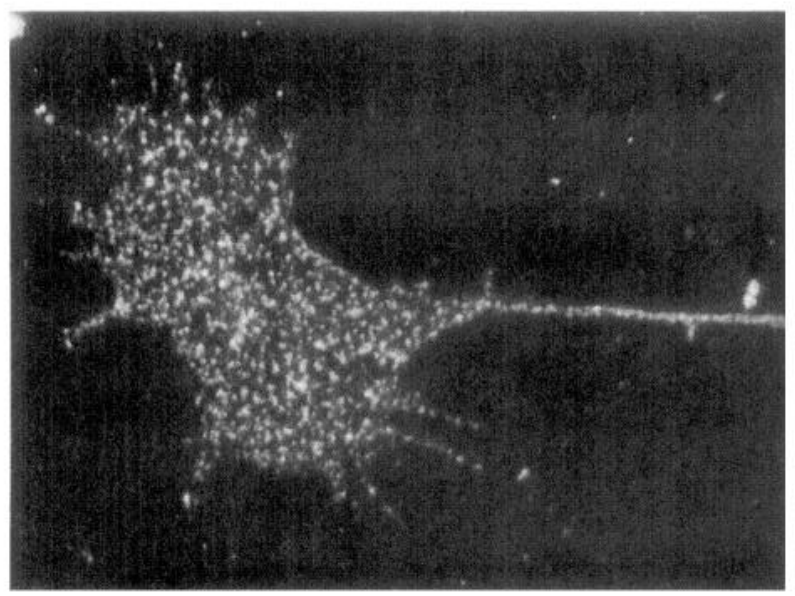

Figure 6. Immunoreactivity to anti- $\beta 1$ integrin antibody of a growth cone of a dorsal root ganglion cell neuron. There is a uniform distribution of point contacts similar to those observed on PC12 cell growth cones.

substratum interface, punctate immunoreactivity to $\beta 1$ and $\alpha 1$ integrin subunits was observed (Fig. $5 A, B$ ). The density of the integrin deposits was higher at the cell periphery than at the center of the cell body (Fig. $5 A, B$ ). Moreover, labeling was associated only with the lower cell surface (x,z-plane; Fig. 5A, $B$, right panel). The integrins on the upper surface were removed by the detergent, presumably because they are not strongly associated with the cytoskeleton. No immunoreactivity to $\alpha 3$ remained after detergent extraction (Fig. $5 D$ ), in accordance with the results obtained by Western blotting (Fig. 2).

To determine if integrin localization to point contacts was present in primary cultures of neurons, we examined chick dorsal root ganglion cells. As observed for PC12 cells, there was no evidence of focal contact. The $\beta 1$ immunoreactivity was restricted to point contacts uniformly distributed over the growth cone surface (Fig. 6).

\section{Integrin distribution compared to vinculin, talin, and p125}

Focal contacts in non-neuronal cells contain a characteristic repertoire of proteins (Burridge et al., 1988). To determine whether the punctate integrin complexes on PC12 cells had similar protein composition to the integrin aggregations that have been characterized at sites of focal contacts in other cells, we examined by immunocytochemistry the distribution of vinculin, talin, and p125 $5^{\mathrm{FAK}}$. In whole cells that were fixed before permeabilization, a grainy distribution of vinculin was observed, with bright spikes of immunoreactivity at the tips of the filopodia. In cytoskeletal preparations, vinculin showed only a partial colocalization with integrin receptors (Fig. $7 A-D$ ). Coincident immunoreactivity was restricted to some portions of the cell periphery and the tips of some growth cone filopodia. There was no specific colocalization of vinculin with $\beta 1$ integrin over other peripheral regions or the entire central region of the cell (Fig. $7 C, D$ ).

Talin immunoreaction was grainy in whole PC12 cells and in extracted cytoskeletons. There was no specific accumulation of talin within punctate deposits where integrin receptors were clustered (Fig. $7 E-H)$ ). The monoclonal antibody against talin used in this study stained focal contacts in chick fibroblasts, and in PC12 cells it recognized on Western blots a band of the expected apparent molecular weight of $225 \mathrm{kDa}$.
The protein $\mathrm{p} 125^{\mathrm{FAK}}$ is a tyrosine kinase that colocalizes with integrin receptors at sites of focal contacts (Kornberg et al., 1991; Schaller et al., 1992). To examine if this kinase was a component of point contacts, too, we used double immunofluorescence with the anti- $\beta 1$ antibody and anti-p $125^{\mathrm{FAK}}$ antibody. We observed the typical punctate staining for the $\beta 1$ subunit (Fig. $8 B$ ) but no immunoreactivity for the $125^{\mathrm{FAK}}$ protein (Fig. $8 A$ ). To confirm the absence of staining of point contacts, we examined rat astrocytes that have both focal contacts and point contacts (Tawil et al., 1993). In these cells, strong immunoreactivity for $\mathrm{p} 125^{\mathrm{FAK}}$ was observed at sites of focal contact in contrast to the lack of immunoreactivity of the point contacts (Fig. $8 C, D$ ).

\section{Discussion}

Previous studies have reported that integrins function in cell matrix adhesion in PC12 cells (Tomaselli et al., 1988, 1990; Turner et al., 1989). The $\alpha 1 \beta 1$ is the dominant integrin-mediating neurite outgrowth, and the $\alpha 3 \beta 1$ heterodimer is a relatively weak receptor (Tomaselli et al., 1990). In the present work, we have explored the distribution of integrins on PC12 cells, their association with the cytoskeleton, and factors that control the association. Our results indicate that unlike focal contacts in well-spread non-neuronal cells, integrins on $\mathrm{PC} 12$ cells are found in a punctate distribution uniformly over the cell surface. These punctate deposits lacked talin, and p125 12 FAK colocalization, and many lacked vinculin. Therefore, the cytoskeletal assembly that underlies PC1 2 cell point contacts on cell bodies and growth cones is distinct from that of the focal contacts observed in other cells. Although there were no obvious focal contacts observed by anti-integrin immunocytochemistry, the codistribution of vinculin and integrin at the cell periphery and tips of the filopodia suggests that these sites may be functionally equivalent to focal contacts. However, all point contacts on the lower cell surface are potential sites of integrin association with the detergent-resistant cytoskeleton because $\alpha 1$ and $\beta 1$ subunits were retained uniformly on the basal cell surface following extraction with nonionic detergents. In contrast, $\alpha 3 \beta 1$ heterodimers, which like $\alpha 1 \beta 1$ heterodimers recognize laminin, associate only weakly with the cytoskeleton. The differential retention of these laminin receptors with the cytoskeleton appears to reflect the efficacy of these two integrins in binding to ligands in the substratum (discussed below) and in mediating cell substratum attachment in PC12 cells (Tomaselli et al., 1990).

\section{Point contacts}

In non-neuronal cells, strong cell adhesion occurs through integrin receptor linkages to the cytoskeleton at sites of focal contacts (Burridge et al., 1988). Focal contacts have been studied extensively and their structure has proven valuable in identifying candidate proteins associated with integrins. However, other integrin-containing structures, termed point contacts, podosomes, or rosette adhesions, have been reported to coexist with focal contacts, with the latter being more prevalent in transformed cells (Burridge et al., 1988; Otto, 1990). It has been noted in several studies that these point contacts in non-neuronal cells exhibit some structural differences from focal contacts (Burridge et al., 1988; Nermut et al., 1991) and, more recently, that integrins in point contacts function in substratum adhesion, especially during early stages of cell spreading (Tawil et al., 1993).

We report here that in at least some neural cells $\beta 1$ integrins are found exclusively in point contacts. Point contacts are pres- 

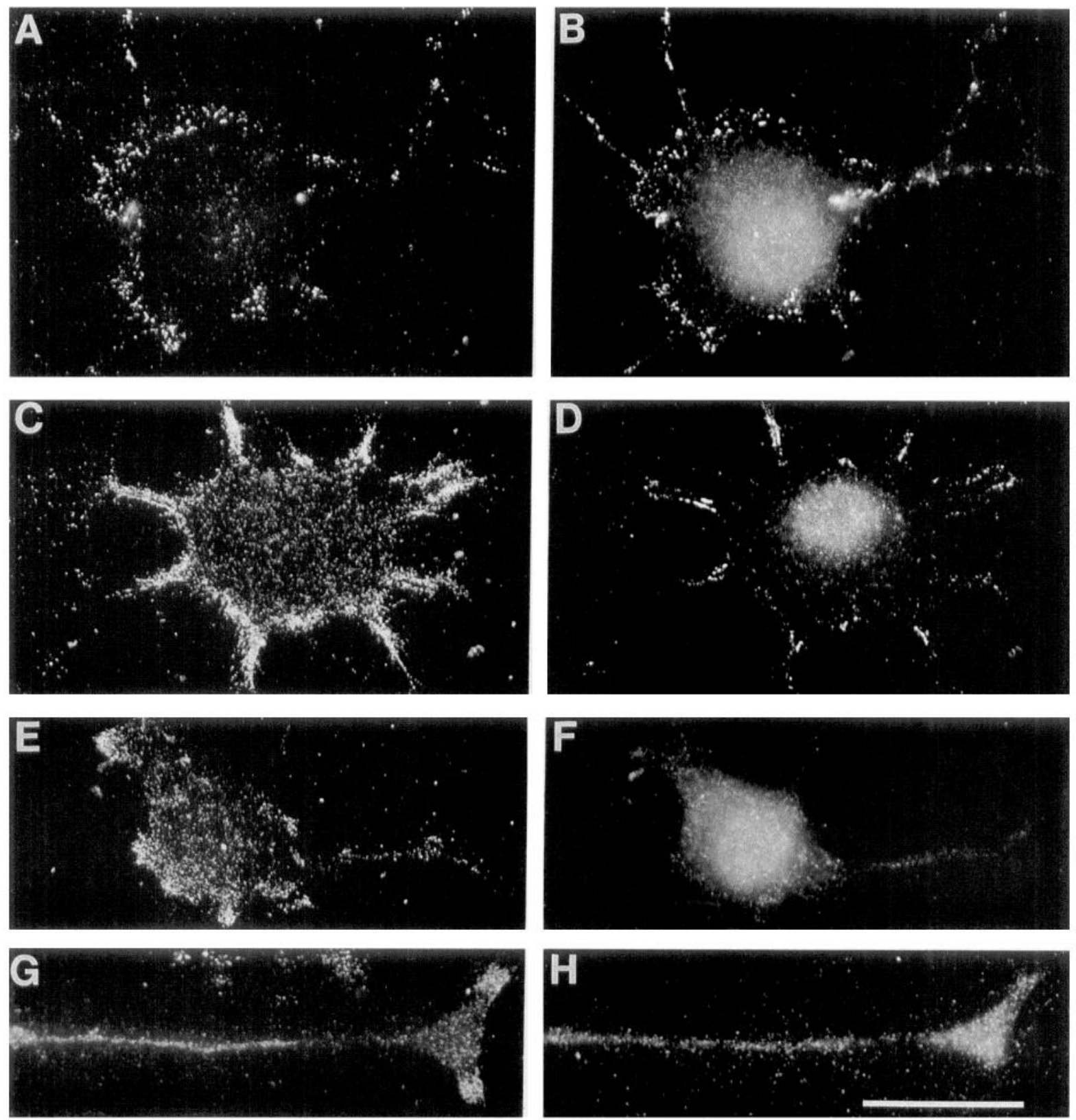

Figure 7. Distribution of $\beta 1$ integrin, talin, and vinculin in cytoskeletal ghosts: double immunofluorescence using the anti- $\beta 1(A, C, E$, and $G)$ and anti-vinculin $(B$ and $D)$ or anti-talin $(F$ and $H)$ antibodies. Note the codistribution of $\beta 1$ and vinculin in point contacts at the cell margin and neurite tips, but an absence of colocalization in the central region of the cell. Talin shows a reciprocal pattern to vinculin, but there is not obvious colocalization with $\beta 1$ in point contacts. Scale bar, $20 \mu \mathrm{m}$.

ent on the cell body, neurites, and growth cones of PC12 cells, as well as primary neurons in culture. Consistent with these observations on the absence of focal contacts in neurons cultured on laminin, interference reflection optical studies show few regions of close growth cone-substratum apposition, and regions of membrane associated with substrate appear as dark spots (Gunderson, 1988; Zheng et al., 1993).

The functional role of point contacts is controversial. Based on their appearance in transformed cells, and because the normal cells in which they are found tend to be invasive and express proteases at their cell surface, it has been suggested that they may be involved in local degradation of ECM (Burridge et al., 1988). Another suggestion is that they are a normal adhesion structure found in highly motile cells (Nermut et al., 1991). The results of studies on carcinoma cell adhesion and spreading have suggested that integrins in point contacts are unable to interact with the cytoskeleton (Wayner et al., 1991). Recent antibody blocking experiments performed with astrocytes that express both point contacts and focal contacts demonstrate that point contacts can be functional sites of adhesion (Tawil et al., 1993). Our finding that point contacts are the only integrin-containing adhesion structure in $\mathrm{PC} 12$ cells, and that anti-integrin antibodies block PC12 cell adhesion (Turner et al., 1989), strongly supports the notion that point contacts are functional in cell attachment and growth cone motility.

Talin and p125 $5^{\mathrm{FAK}}$, both components of focal contacts, do not colocalize exclusively with integrins at point contacts. The antibodies used for these studies recognized proteins from $\mathrm{PC} 12$ 

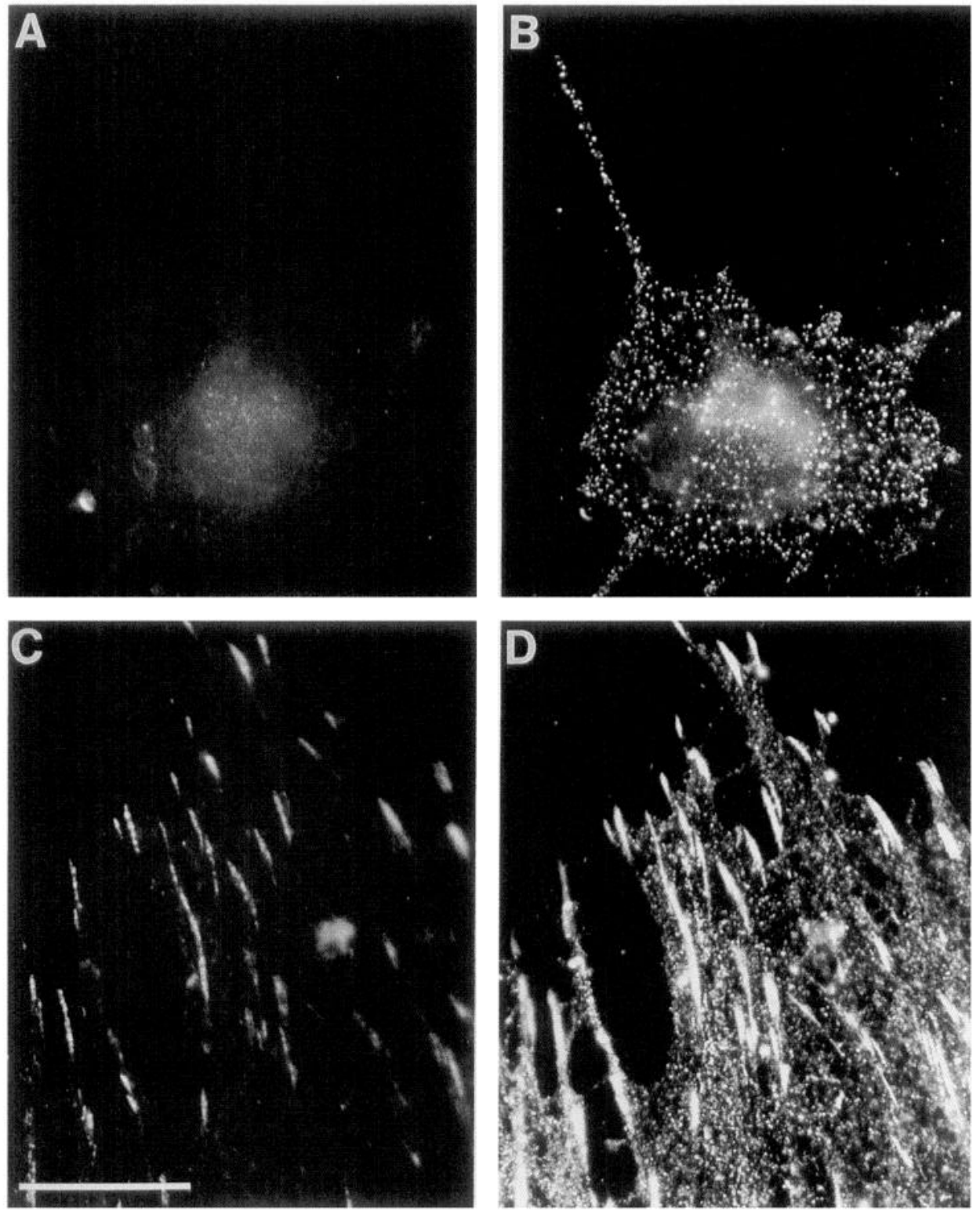

Figure 8. Differences in immunoreactivity to $\mathrm{p} 125^{\mathrm{FAK}}$ in $\mathrm{PC} 12$ cells and astrocytes. PC12 cells grown on laminin $(A$ and $B$ ) or rat astrocytes grown on polylysine $(C$ and $D$ ) were double labeled with anti- $\beta 1$ ( $B$ and $D)$ and anti-p125 FAK antibodies $(A$ and $C$ ). Immunoreactivity to $\mathrm{p} 125^{\mathrm{FAK}}$ is present at focal contacts in astrocytes, but is absent from point contacts in both astrocytes and PC1 2 cells. Scale bar, $20 \mu \mathrm{m}$. cells of the appropriate molecular weight (data not shown), and labeled focal contacts in fibroblasts or astrocytes. Talin immunoreactivity was present in PC12 cells, as previously reported (Letourneau and Shattuck, 1989), but the overall grainy distribution was more suggestive of a generalized localization to the membrane cytoskeleton, than to selective localization within point contacts. The complete absence of p125 12 from point contacts in both $\mathrm{PC} 12$ cells and astrocytes raises the possibility that an alternate nonreceptor tyrosine kinase, perhaps one of the several known to be enriched in growth cones (Bixby and Jhabvala, 1993), may play a role in point contact function.

Vinculin immunoreactivity was restricted to the cell periphery (Halegoua, 1987), where it tended to overlap with contacts present at the cell periphery and the tips of filopodia, a finding that raises the possibility that two distinct classes of point contact exist with respect to the presence or absence of vinculin. These vinculin foci may represent the strongest adhesion sites because they are particularly resistant to loss during detergent extraction (see Fig. $7 A, B$ ). Other investigations have shown that vinculin is absent from highly motile structures (invadopodia) formed by transformed cells (Mueller et al., 1989) and from point contacts in astrocytes (Tawil et al., 1993). We report here that many point contacts do not colocalize with vinculin. Therefore, in neurons, the main adhesion structure exhibits striking differences from those of the better characterized focal contacts (Burridge et al., 1988; Luna and Hitt, 1992).

\section{Differences between $\alpha 1$ and $\alpha 3$ association with the detergent-resistant cytoskeleton}

Prior studies have identified $\alpha 1 \beta 1$ and $\alpha 3 \beta 1$ as the two $\beta 1$ integrin heterodimers and characterized their relative contributions to PC12 cell adhesion to laminin and collagen (Turner et al., 1989; Tomaselli et al., 1988, 1990). Here we have explored the ability of these two heterodimers to associate with the cytoskeleton before and after cell attachment. On collagen or laminin but not on polylysine, half of the $\alpha 1$ and half of the $\beta 1$ integrin subunits were retained with the Triton X-100-insoluble cytoskeleton. This biochemical result is consistent with confocal 
studies where only integrins on the basal cell surface were found to be retained with the cytoskeletal ghosts. The integrin receptors on unattached cells and the upper cell surface of attached cells were detergent soluble. The $\alpha 3$ subunit, however, always remained soluble under our experimental conditions. This result suggests that either the detergent disrupted the noncovalent links between the $\alpha 3$ and $\beta 1$ monomers or that the complete $\alpha 3 \beta 1$ heterodimeric receptor was detergent soluble. We favor the latter interpretation because $\alpha 3 \beta 1$ heterodimers are routinely immunoprecipitated from PC12 cells following extraction with nonionic detergents (Tomaselli et al., 1990, 1993). This relatively poor association of $\alpha 3 \beta 1$ with the cytoskeleton would suggest that the generally weak efficacy of $\alpha 3 \beta 1$ in cell attachment is not simply a function of low affinity for a particular laminin isoform (Tomaselli et al., 1993) but additionally results from weak associations with the cytoskeleton.

Finally, our data allow us to fill in several details of integrinsubstratum adhesion in neurons. In prior models, it has been unclear whether integrins are constitutively linked with the cytoskeleton recruited into substratum contacts by interaction with immobilized ligands or whether attachment triggers cytoskeletal association. Our data support the latter model by showing that all integrins are found in the detergent-soluble pool prior to attachment, but following attachment to laminin or collagen they associate tightly with the cytoskeleton. Consistent with this, only those integrins at the lower cell surface are retained with the cytoskeleton. Moreover, since attachment of PC12 cells to polylysine is relatively ineffectual at transducing these events, it appears that ligand-coated substrata are necessary. We reason, then, that integrins on filopodia extending unattached from the margins of growth cones have integrins uniformly in small aggregates on their surfaces. Interaction with an immobilized ligand then triggers association with the cytoskeleton and, possibly at the same time, contractile events responsible for pulling (Heidemann et al., 1990) the growth cone over the substratum.

\section{References}

Akiyama SK, Yamada KM (1987) Biosynthesis and acquisition of biological activity of the fibronectin receptor. J Biol Chem 262:1753617542.

Arregui C, Busciglio J, Caceres A, Barra HS (1991) Tyrosinated and detyrosinated microtubules in axonal processes of cerebellar macroneurons grown in culture. $\mathbf{J}$ Neurosci Res 28:171-181.

Bauer JS, Varner J, Schreiner C, Kornberg L, Nicholas R, Juliano Ri (1993) Functional role of the cytoplasmic domain of the integrin $\alpha 5$ subunit. J Cell Biol 122:209-221.

Bershadsky AD, Tint IS, Neyfakh AA Jr, Vasiliev JM (1985) Focal contacts of normal and RSV-transformed quail cells. Hypothesis of the transformation-induced deficient maturation of focal contacts. Exp Cell Res 158:433-444.

Bixby JL, Jhabvala P (1993) Tyrosine phosphorylation in early embryonic growth cones. J Neurosci 13:3421-3432.

Burridge K, rath K, Kelly T, Nuckolls G, Turner C (1988) Focal adhesions: Transmembrane junctions between the extracellular matrix and the cytoskeleton. Annu Rev Cell Biol 4:487-525.

Carbonetto S, Evans D, Cochard P (1987) Nerve fiber growth in culture on tissue substrata from central and peripheral nervous systems. $\mathbf{J}$ Neurosci 7:610-620.

Carpen O, Pallai P, Staunton DE, Springer TA (1992) Association of intercellular adhesion molecule-1 (ICAM-1) with actin-containing cytoskeleton and $\alpha$-actinin. J Cell Biol 118:1223-1234.

Chan BMC, Kassner PD, Schiro JA, Byers HR, Kupper TS, Hemler MW (1992) Distinct cellular functions mediated by different VLA integrin $\alpha$ subunit cytoplasmic domains. Cell 68:1051-1060.

Cohen J, Nurcombe V, Jeffrey P, Edgar D (1989) Developmental loss of functional laminin receptors on retinal ganglion cells is regulated by their target tissue, the optic tectum. Development 107:381-387. de Curtis I, Quaranta V, Tamura RN, Reichardt LF (1991) Laminin receptors in the retina: sequence analysis of the chicken integrin $\alpha 6$ subunit. Evidence for transcriptional and posttranslational regulation. J Cell Biol 113:405-416.

Drubin DS, Kobayashi D, Kellogg M, Kirschner M (1988) Regulation of microtubule protein levels during cellular morphogenesis in nerve growth factor-treated PC12 cells. J Cell Biol 106:1583-1591.

Greene LA, Alctta JM, Rukenstein A, Green SH (1987) PC12 Pheochromocytoma cells: culture, nerve growth factor treatment, and experimental exploitation. Methods Enzymol 147:207-216.

Gunderson RW (1988) Interference reflection microscopic study of dorsal root growth cones on different substrates: assessment of growth cone-substrate contacts. J Neurosci Res 21:298-306.

Halegoua S (1987) Changes in the phosphorylation and distribution of vinculin during nerve growth factor induced neurite outgrowth. Dev Biol 121:97-104.

Hayashi Y, Haimovich B, Reszka A, Boettiger D, Horwitz A (1990) Expression and function of chicken integrin $\beta \mathrm{I}$ subunit and its cytoplasmic domain mutants in mouse NIH 3 T 3 cells. J Cell Biol 110: 175-184.

Heidemann SR, Lamoureux P, Bauxbaum RE (1990) Growth cone bchavior and production of traction forcc. J Ccll Biol 1 11:1949-1957.

Hynes RO (1992) Integrins: versatility, modulation, and signaling in cell adhesion. Cell 69:11-25.

Kornberg LJ, Earp HS, Turner CE, Prockop C, Juliano RL (1991) Signal transduction by integrins: increased protein tyrosine phosphorylation caused by clustering of $\beta 1$ integrins. Proc Natl Acad Sci USA 88:8392-8396.

Lefcort F, Venstrom K, McDonald JA, Reichardt LF (1992) Regulation of expression of fibronectin and its receptor, $\alpha 5 \beta 1$, during development and regeneration of peripheral nerve. Development 116: 767-782.

Letourneau PC, Shattuck TA (1989) Distribution and possible interactions of actin-associated proteins and cell adhesion molecules of nerve growth cones. Development 105:505-519.

Letoumeau PC, Condic ML, Snow DM (1992) Extracellular matrix and neurite outgrowth. Curr Opin Genet Dev 2:625-634.

Luna EJ, Hitt AL (1992) Cytoskeleton-plasma membrane interactions. Science 258:955-964.

Morris JE, Lasek RJ (1984) Monomer-polymer equilibria in the axon: direct measurement of tubulin and actin as polymer and monomer in axoplasm. J Cell Biol 98:2064-2076.

Mueller SC, Kellie T, Dai M, Dai H, Chen W-T (1989) Dynamic cytoskeleton-integrin associations induced by cell binding to immobilized fibronectin. J Cell Biol 109:3455-3464.

Nermut MV, Eason P, Hirst EMA, Kellie S (1991) Cell/substratum adhesions in RSV-transformed rat fibroblasts. Exp Cell Res 193:382397.

Otey CA, Pavalko FM, Burridge K (1990) An interaction between $\alpha$-actinin and the $\beta 1$ integrin subunit in vitro. J Cell Biol 111:721729.

Otto JJ (1990) Vinculin. Cell Motil Cytoskel 16:1-6.

Reichardt LF, Tomaselli KF (1991) Extracellular matrix molecules and their receptors: functions in neural development. Annu Rev Neurosci 14:531-570.

Reszka AA, Hayashi Y, Horwitz AF (1992) Identification of amino acid sequences in the integrin $\beta 1$ cytoplasmic domain implicated in cytoskeletal association. J Cell Biol 117:1321-1330.

Schaller MD, Borgman CA, Cobb BS, Vines RR, Reynolds AB, Parsons JT (1992) pp125 FAK, a structurally distinctive protein-tyrosine kinase associated with focal adhesions. Proc Natl Acad Sci USA 89: 5192-5196.

Schoenfeld TA, McKerracher L, Obar R, Vallee RB (1989) MAP IA and MAP $1 B$ are structurally related microtubule-associated proteins with distinct developmental patterns in the CNS. J Neurosci 9:17121730.

Solowska J, Guan J-L, Marcantonio EE, Trevithick JE, Buck CA, Hynes RO (1989) Expression of normal and mutant avian integrin subunits in rodent cells. J Cell Biol 109:853-861.

Solowska J, Edelman JM, Albelda SM, Buck CA (1991) Cytoplasmic and transmembrane domains of integrin $\beta 1$ and $\beta 3$ subunits are functionally interchangeable. J Cell Biol 114:1079-1088.

Tawil NJ, Houde M, Blacher R, Esch F, Reichardt LF, Turner DC, 
Carbonetto S (1990) The $\alpha 1 / \beta 1$ integrin heterodimer functions as a dual laminin/collagen receptor in neural cells. Biochemistry 29: $6540-6544$.

Tawil N, Wilson P, Carbonetto S (1993) Integrins in point contacts mediated cell spreading: factors that regulate integrin accumulation in point contacts vs. focal contacts. J Cell Biol 20:261-271.

Tomaselli KJ, Damsky CH, Reichardt LF (1988) Purification and characterization of mammalian integrins expressed by a rat neuronal cell line (PC12): evidence that they function as $\alpha / \beta$ heterodimeric receptors for laminin and type IV collagen. J Cell Biol 107:12411252.

Tomaselli KJ, Hall DE, Flier LA, Gehlsen KR, Turner DC, Carbonetto $S$, Reichardt LF (1990) A neuronal cell line (PC12) express two $\beta$-class integrins $-\alpha 1 \beta 1$ and $\alpha 3 \beta 1$-that recognize different neurite outgrowth-promoting domains in laminin. Neuron 5:651-662.

Tomaselli KJ, Doherty P, Emmett CJ, Damsky C, Walsh FS, Reichardt LF (1993) Expression of $\beta 1$ integrin in sensory neurons of the dorsal root ganglion and their functions in neurite outgrowth on two laminin isoforms. J Neurosci Bull 13:4880-4888.

Toyota B, Carbonetto S, David S (1990) A dual laminin/collagen receptor acts in peripheral nerve regeneration. Proc Natl Acad Sci USA 87:1319-1322.

Turner DC, Flier LA, Carbonetto S (1989) Identification of a cellsurface protein involved in PC12 cell-substratum adhesion and neurite outgrowth on laminin and collagen. J Neurosci 9:3287-3296.

Wayner EA, Orlando RA, Cheresh SA (1991) Integrins $\alpha \mathrm{V} \beta 3$ and $\alpha \mathrm{V} \beta 5$ contribute to cell attachment but differentially distribute on the cell surface. J Cell Biol 113:919-929.

Ylänne J, Chen Y, O'Toole TE, Takada Y, Ginsberg MH (1993) Distinct functions of integrin $\alpha$ and $\beta$ subunit cytoplasmic domains in cell spreading and formation of focal contacts. J Cell Biol 122:223233

Zheng J, Buxbaum RE, Heidemann SE (1993) A cytomechanical investigation of growth cone adhesion. Mol Biol Cell 4:255a. 